- ACORN Australan college of | JOURNAL OF PERIOPERATIVE NURSING

Volume 34 | Issue 2

Article 4

$5-11-2021$

\title{
Ergoophthalmological risks associated with dry eye in the operating room
}

Follow this and additional works at: https://www.journal.acorn.org.au/jpn

Part of the Occupational and Environmental Health Nursing Commons

c) (i)

This work is licensed under a Creative Commons Attribution 4.0 License.

\section{Recommended Citation}

Nemli, Aslı Dr.; Gümüş, Koray Prof.Dr.; and Başer, Mürüvvet Prof.Dr. (2021) "Ergoophthalmological risks associated with dry eye in the operating room," Journal of Perioperative Nursing: Vol. 34 : Iss. 2 , Article 4. Available at: https://doi.org/10.26550/2209-1092.1115

https://www.journal.acorn.org.au/jpn/vol34/iss2/4

This Discussion paper is brought to you for free and open access by Journal of Perioperative Nursing. It has been accepted for inclusion in Journal of Perioperative Nursing by an authorized editor of Journal of Perioperative Nursing. 


\section{Authors \\ Aslı Nemli \\ PhD \\ Department of General Surgery, Ege \\ University Hospital}

Prof. Dr. Koray Gümüş

Department of Eye Diseases and Surgery,

Ankara Memorial Hospital

Prof. Dr. Mürüvvet Başer

Faculty of Health Sciences, Department of Nursing, Erciyes University

\section{Corresponding author}

Aslı Nemli

PhD

Department of General Surgery, Ege

University Hospital

nmli.asli@gmail.com

\section{Ergoophthalmological risks associated with dry eye in the operating room}

\section{Abstract}

Dry eye disease is one of the most common pathologies of the ocular surface. In parallel with increased screen exposure, environmental changes and modern life in recent years, the prevalence and severity of dry eye have been increasing. Ergoophthalmology is the study of visual ergonomic conditions. It is concerned with injuries to the eyes caused by occupational factors and uses a multidisciplinary approach to understand the causes of occupational visionrelated and ocular diseases and to prevent and manage these conditions. Vision-related risks in the operating room are critical for patients and health care providers. There are many predisposing factors in the operating room environment - air conditioning, constant humidity, constant room temperature, intense lighting, surgical smoke, anaesthetic gases and the use of irritant chemicals and biological aerosols. In addition, surgery itself is a critical task requiring long-term mental effort and concentration which can also predispose operating room staff to dry eye disease. In this review, we discuss occupational and environmental ergoophthalmological risk factors for dry eye disease in the operating room.

Keywords: dry eye, ergoophthalmology, operation room, health workers

\section{Introduction}

Dry eye disease is one of the most common ocular morbidities. It is a multifactorial, chronic pathology of the ocular surface and tear film, characterised by tear film instability and visual disturbances and potentially results in injury to the ocular surface. In the majority of cases, it is accompanied by increased osmolarity of the tear film with increased evaporation and ocular surface inflammation?.

The prevalence of dry eye disease varies between five to 50 per cent in adults worldwide and may increase up to 75 per cent in postmenopausal women aged above 50 years. While it is seen in only 2.7 per cent of young adults aged between 18 and 45 years ${ }^{2}$, recent studies have emphasised the increased prevalence of dry eye among young adults aged between 18 and 34 years due to the increased use of digital screens ${ }^{3,4}$. Although advanced age and female sex are the main known risk factors, occupational activities and environmental factors have been shown to be closely associated with increased prevalence and severity of dry eye disease ${ }^{2}$. Occupational activities include reading, driving and screen use which all require maximal mental effort. Environmental factors, where blinking is inhibited involuntarily due to the evaporative and irritant effects on the ocular surface, include low humidity, cold air, artificial indoor heating and air conditioning, air pollutants such as dust and smoke, liquid or gas chemicals such as ozone and formaldehyde, biological agents such as demodex, pollen and fungi, and cigarette smoke ${ }^{5,6}$. Several studies have demonstrated that poor indoor air quality in modern office buildings, low relative humidity, high room temperature, high air flow, scents and other chemical pollutants are the main causes of 
ocular symptoms ${ }^{7-9}$. These symptoms initially cause oxidative stress and injury to the ocular surface resulting in itching, burning and lacrimation. Patients present with pain, foreign body sensation and, in later stages, blurred vision as the trigeminal nerves are affected ${ }^{10,11}$. In an epidemiological study, Azuma et al.12 examined the relationship between indoor air quality and buildingrelated symptoms of office workers and found a significant correlation between low ambient humidity and eye irritation. In another study, the incidence of ocular diseases and eye fatigue were significantly higher among office workers ${ }^{13}$. Considering their use of computers for long hours, occupational activities with a high level of visual burden and their working environment, office personnel and cabin attendants are considered a high-risk group ${ }^{14}$. In addition, dry eye has been associated with anxiety and depression, decreased effective working time and productivity and limited psychological, physical and social functioning, particularly among office workers ${ }^{15-17}$. A limited number of studies has also demonstrated that the risk of dry eye disease is higher by 56 per cent in operating room staff and laboratory technicians than the general population ${ }^{18-20}$.

To the best of our knowledge, there is no research examining dry eye disease in operating room staff. Additionally, there is no standard for prevention or management of dry eye disease in national and international reports of occupational health practices for operating room staff. In previous studies regarding ergonomic principles of surgery, musculoskeletal disorders and fatigue are the most common occupational diseases or injuries caused by non-ergonomic factors ${ }^{21,22}$; however, Anshel ${ }^{23}$ commented on the relationship between musculoskeletal disorders and visual performance - that the eyes commanded the body's action and adapted to the viewing environment when vision was poor or unsatisfactory. Therefore, the use of intense lighting, ventilation filters, irritant chemicals and surgical laser, and the presence of surgical smoke, anaesthetic gases and biological aerosols in the hospital setting, as well as advanced medical technology, call for ergoophthalmological studies. In this review, we discuss occupational and environmental ergoophthalmological risk factors of dry eye disease among operating room staff.

\section{The effects of evaporation and blinking}

The proposed vicious cycle of the pathology of dry eye disease is tear film instability, leading to hyperosmolarity and inflammation of the ocular surface ${ }^{24}$. Accordingly, the disease is classified into two main categories: hyperevaporation related to meibomian gland dysfunction (MGD) which is characterised by excessive evaporation of the tear film, and aqueous deficiency caused by reduced aqueous production from the lacrimal glands ${ }^{25}$. Aqueous deficiency occurs in about 10 per cent of cases of ocular symptoms related to dry eye disease, while hyperevaporative or mixed type is seen in more than 80 per cent of cases $^{26}$.

It has been well documented that evaporation plays a key role in the onset and maintenance of dry eye disease and is the main cause of hyperosmolarity and ocular surface damage; thereby, leading to the loss of epithelial and goblet cells directly or through inflammation ${ }^{24}$. Tear film osmolarity is the indicator of the balance between the tear production, evaporation, drainage and absorption ${ }^{27,28}$. As a result, tear film osmolarity is primarily affected by the body's hydration, tear film lipid layer, palpebral fissure width, frequency of eye blinking, tear film stability and environmental factors.

Previous studies have suggested that the blink reflex is the main mechanism of an intact ocular surface and tear film osmolarity ${ }^{2,29}$. Blinking occurs on a voluntary basis or through motor innervation or reflex in healthy individuals. The blink reflex is the rapid closing of the eyelid which is evoked in response to ocular, acoustic, trigeminal or visual stimuli, as well as external stimuli such as motor movements ${ }^{30}$. Blinking spreads, mixes and distributes the tear film components onto the ocular surface and secretion of lipids from the meibomian glands is stimulated through the muscle movement during eye blinking. Several studies have supported the potential link between incomplete blinking, MGD and development of evaporative dry eye disease. In a study investigating the impact of blinking on tear film parameters, ocular surface characteristics and dry eye symptomology, incomplete blinking was associated with a two-fold increased risk of dry eye disease ${ }^{31}$. In addition, reduced blink rate and incomplete blinking during a visual display terminal task were associated with decreased tear film stability and dry eye disease-related symptoms. This can be attributed to decreased secretion of the meibomian glands and reduced quality of the meibomian lipids and the tear film lipid layer becomes thickened ${ }^{32,33}$.

\section{Ergoophthalmological risk factors in the operating room}

In recent years, a serious concern has been raised about the harmful effects of occupational and environmental factors on dry eye disease. In the operating room 
these factors include the burden of surgical procedures, the use of constant temperature and humidity, high-efficiency particulate air (HEPA) filters, operating room lighting panels, surgical laser and electrocautery instruments, chemical antiseptics, disinfectants and sterilising agents. In addition, operating rooms are likely to contain anaesthetic gases, surgical smoke, ambient particle load, and microbial agents.

\section{Surgical procedure}

Surgery is the cornerstone of treatment in many cases. Although there is no standard duration for surgical procedures, it has been found to vary between 42 and 504 minutes in previous studies ${ }^{34}$. Surgery, itself, is a critical task which requires long-term mental effort and concentration and is associated with reduced frequency of eye blinking and increased evaporation - both potential precipitating factors for the development of dry eye disease. It is well established that reduced frequency of eye blinking during visual tasks requiring long-term mental effort and concentration is associated with increased evaporation of the tear film ${ }^{14,19}$. Previous studies have also shown that there is a significant inverse relationship between the frequency of eye blinking and tasks requiring long-term mental effort ${ }^{30}$. The frequency of eye blinking is involuntarily inhibited resulting in increased evaporation during cognitive, mental or visual tasks. To illustrate, the frequency of blinking is reduced to six to ten times per minute while using a computer screen but ranges from 15 to 20 times per minute in standard room temperature and humidity (i.e. 22 o C and 40 per cent humidity) in healthy individuals, although this rate may vary in each individual depending on the personal behavior patterns and environmental factors ${ }^{5,35}$. Similarly, occupations and tasks which require high visual and cognitive demands have been proven to be the most common occupational risks for increased dry eye symptoms, underlining the relationship between the increased incidence of dry eye disease and occupational activities requiring a high level of cognitive and visual skills ${ }^{10,30}$.

\section{Physical environment of the operating room}

The quality of the environment is affected by several components such as ambient temperature, humidity, air conditioning, air flow, lighting and noise. It has been well established in many studies that the ambient air of the operating room is contaminated by pollutants including dust particles loaded with bacteria, textile fibers, respiratory aerosols and surgical smoke, thereby leading to the increased rate of surgical site infections and threatening the health of health care workers ${ }^{36-38}$. In accordance with patient and health care worker safety, the cleanroom standards for the operating room using constant room temperature, constant humidity, appropriate air conditioning and air flow and have been implemented for many years to keep contaminants and particles outside the room 39,40 .

According to the [European] DIN 1946-4 standard, operating rooms, corridors, sterile goods storage, preand post-operative recovery rooms, surgical hand washing units and the surroundings, analesthesia units and units for the processing of medical devices require the highest hygiene requirements and are defined as cleanrooms (Class I) with no viable microorganisms. Patient rooms, emergency wards, laboratories and radiography units are Class II rooms with no viable microorganisms. For cleanrooms, the particle size should not exceed $0.5 \mu \mathrm{m}$ and the particle count per cubic meter (m3) or cubic foot (ft3) is the determinant for classification ${ }^{37,41}$.

Ventilation systems specifically designed to keep the number of microorganisms and particles within the defined range are indispensable to minimising contamination and providing clean air during surgery in the operating room. In accordance with the cleanroom standards, air pollutants such as air particles, microorganisms, dust and electrocautery smoke are eliminated by air filter systems ${ }^{42,43}$. Currently, traditional or laminar flow diffusers are frequently used in the operating room setting $40,44,45$.

Based on the criterion of a particle size of $0.5 \mu \mathrm{m}$ per unit, laminar flow is provided at a degree of primary turbulence of less than five per cent and $0.24 \mathrm{~m} / \mathrm{sec}$. In contrast to corridors and other closed rooms, the air flow of the operating room is maintained with positive pressure. In addition, at least 15 total air exchange per hour is maintained using special filters for bacterial particles larger than $0.3 \mu \mathrm{m}^{37,46}$. Thanks to the scavenging effect of positive pressure and laminar air flow, the highest protection against particle contamination is ensured. The recommended air filtration and recirculation system in the operating room and intensive care units has two filter beds: the first has 30 per cent efficiency and the second has 90 per cent efficiency. Air particles are removed using special filters with 99.97 per cent efficiency for particles larger than 0.3 $\mu \mathrm{m}$. Scavenging systems, which are used for anaesthetic gas disposal from the operating room, are the fourth major component of the air filtration systems. These systems are external to the air filtration and vacuum systems and are specifically designed to collect gases and 
vapours vented from the breathing circuit and remove them from the operating room ${ }^{43,47}$. Despite the highest level of protection against particle contamination thanks to the scavenging effect of positive pressure and laminar air flow, the increased air circulation, constant humidity and constant temperature increase the precorneal air exchange, eventually leading to excessive ocular evaporation ${ }^{5}$. Similarly, high horizontal or downward air velocity around the head region enhances the evaporation rate of the tear film, accelerates a temperature decrease, particularly in the cornea, and results in irritation of the ocular surface?

In accordance with operating room standards, the room air should be maintained at 21 to $24^{\circ} \mathrm{C}$ and the humidity should be maintained at 30 to 60 per cent to minimise static electricity discharges ${ }^{43}$. Previous studies show that low ambient humidity (particularly less than 40 per cent) and air flow provided by the air conditioning and ventilation systems and fan coil units had adverse effects on the ocular structures including irritation, burning and hyperaemia. Also, unfavorable environmental factors such as temperature, humidity and air flow resulted in increased severity of ocular symptoms such as itching, redness, pain and decreased visual acuity ${ }^{48,49,50}$. In low-humidity environments, tear film instability increased and the ocular surface became more vulnerable?

Operating room lighting fixtures consist of a single- or multiplelight head assembly attached to a suspension arm. They can be mounted at a fixed point on the ceiling or wall. Sterilisable handles allow the surgeon to adjust the position of the light easily. Surgical lights are designed to enable optimal visualisation of the surgical site. The surgical lighting requirements vary depending on the type, brand and model of the lighting system. The illuminance of a surgical light head is measured in lux and should not exceed 160000 lux $x^{51}$. In general, standard lighting uses 100 lux illuminance for general lighting of the operating room and 50000 to 100000 lux illuminance for the operating table. Surgical lamps can be classified into two main types as conventional (incandescent) and light-emitting diode (LED) ${ }^{52,53}$. There is no study investigating the effect of high-intensity lighting on the operating room staff in the literature; however, eye fatigue was reported in 59.6 per cent of cleanroom microscope workers ${ }^{54,55}$. Altogether, these findings indicate that, similar to artificial air conditioners, wind, continuous air flow conditioning and ventilation systems, constant temperature and humidity may increase the rate of evaporative dry eye disease among operating room staff. Considering the high level of illuminance in the operating room, surgical lighting should be considered an ergoophthalmological risk factor.

\section{Chemical irritants (antiseptics, disinfectants and sterilising agents)}

Surgical asepsis, also referred to as aseptic technique, is the mainstay of safe surgery. The most frequently used chemicals for aseptic technique in the operating room include phenol and phenol derivatives (hexachlorophene), chlorine and chlorine derivatives (hypochlorite), iodine and iodine derivatives (iodophor, povidone-iodine), aldehydes (formaldehyde, glutaraldehyde), alcohols (ethyl alcohol, isopropyl alcohol), ammonium compounds (chlorhexidine) and hydrogen peroxide ${ }^{56}$. Previous studies examined the irritating effects of these chemicals on the cornea and ocular surface ${ }^{57,58}$. In a study, acute exposure to chemicals such as ozone, volatile organic compounds, cigarette smoke, nitrogen oxide and combustion products caused irritation of the ocular surface, while chronic exposure was associated with nerve and muscle injury ${ }^{24}$.

The corneal epithelium is extremely sensitive to chemicals or heat and produces the blink reflex in response to these stimuli. Long-term exposure to such stimuli results in irregularity and edema of the corneal epithelium, thereby leading to prolonged tear break-up time, tear film instability and decreased visual acuity. Formaldehyde is the most potent air pollutant for eye tissues ${ }^{59,60}$. Additionally, stress and injury to the ocular tissues caused by persistent trigeminal stimulation induced by chemicals through the olfactory tract have been shown to be associated with more frequent itching, burning and lacrimation. Besides formaldehyde, acetaldehyde, acetic acid, ammonia, butanol, formic acid, glutaraldehyde and hydrogen peroxide, many other compounds that are used less frequently have irritating effects on the ocular surface ${ }^{60}$. Previous studies reported that peracetic acid showed a wide range of local effects from mild ocular irritation to irreversible tissue damage, depending on the duration and intensity of exposure ${ }^{61,62}$. Sporicidal agents containing hydrogen peroxide, peracetic acid and acetic acid for cleaning and disinfection were also associated with eye irritation symptoms in 44 per cent of hospital cleaning staff and the severity of these symptoms increased with prolonged exposure ${ }^{63,64}$. In another study, eye irritation was the most common adverse event related to the antimicrobial pesticide exposure ${ }^{65}$. Furthermore, glutaraldehyde, 
orthophthaldehyde, peracetic acid, hydrogen peroxide, hypochlorous acid, hypochlorite and formaldehyde, which are frequently used for disinfection in the health care setting, were confirmed to be associated with eye irritation symptoms ${ }^{66}$. The current evidence identifies antiseptics, disinfectants and sterilising agents as the main chemical risks which threaten the lives of health care workers $^{67}$. Based on these findings, antiseptics, disinfectants and sterilising agents, either in liquid or gas form, are all a threat for the development of dry eye disease.

\section{Surgical laser and surgical smoke}

Surgical smoke is the gaseous byproduct caused by thermal tissue destruction during electrosurgery, ultrasonic scalpel dissection and laser tissue ablation or coagulation ${ }^{68}$. As with cigarette smoke, surgical smoke contains potentially hazardous substances including toluene, polyaromatic hydrocarbons, carbon monoxide, furfural, formaldehyde, decane, benzene, acrylonitrile, acrolein, acetylene and acetaldehyde as well as dead and living cellular materials and viruses ${ }^{69}$.

In a study, Sisler et al. ${ }^{70}$ collected 36 surgical smoke samples in real-time in cell culture media using an electrocautery device to cut and coagulate human breast tissue. A field emission scanning electron microscope was then used to characterise airborne particles collected in the cell medium. The authors detected 17 different volatile organic compounds in all samples. Acetaldehyde, ethanol and isopropyl alcohol were the most frequently detected substances in each sample and were present in high concentrations. The main hazardous effects of chemicals produced by surgical smoke are irritation to the eye and upper respiratory tract ${ }^{71}$.

In another study, Ilce et al. ${ }^{72}$ examined the problems related to surgical smoke exposure in 81 nurses and physicians working in the operating room and reported that the most common complaints were headache, watering of the eyes, cough, sore throat, bad odors absorbed in the hair and nausea. In addition, several studies showed that surgical smoke contained a mixture of chemical and biological contaminants, posing a potential hazard for both patients and operating room staff $71,73,74$. Furthermore, downward air flow from the ceiling to the floor (i.e. positive pressure) in the operating room dissipated surgical smoke into the surrounding environment, exposing all surgical personnel to it ${ }^{75}$.

In biomedical applications, laser produces a narrow beam of light with a high level of energy concentrated in a very small area. It is widely used for the removal of vascular tumors, as a scalpel to make the opening incision, to collect incisional and excisional biopsy materials, to cauterise vascular lesions, to cut gingiva and oral mucosa, in coagulation and soft tissue curettage, to treat tumors, and in endoscopic procedures ${ }^{76}$. However, it is not safe for patients and operating room staff due to the radiant intensity it has and potential surgical smoke it produces 77,78 . Corneal and retinal injury related to laser exposure have been described in the literature and transient or permanent loss of vision may occur. In a previous study, exposure to laser beam caused ocular symptoms such as excessive watering of the eyes or foreign body sensation and decreased visual acuity and blurred vision ${ }^{79}$.

\section{Conclusion and recommendations}

In conclusion, dry eye disease is a multifactorial disease of the ocular surface characterised by tear film instability which adversely affects visual functions and quality of life of patients. In the majority of cases, it is caused by excessive evaporation of the tear film and persistent ocular irritation. Besides individual risk factors, in recent years environmental factors and occupations, tasks and habits which require high visual and cognitive demands have been associated with reduced blink rate, ocular symptoms and dry eye disease. Operating rooms are complex, isolated workplaces where different specialties are blended, cutting-edge technology is employed, air quality must be controlled and high standards of cleanliness is required. The nature of surgery, itself, as a critical task requiring long-term mental effort and concentration, often involving prolonged and nonstop working hours, particularly in major surgeries; artificial indoor air conditioning systems, constant humidity, constant room temperature and intense lighting; use of antiseptics, disinfectants and sterilising and sporicidal agents; and, in certain situations, the presence of surgical laser light and surgical smoke should all be considered ergoophthalmological risk factors of dry eye disease among the operating room staff.

\section{References}

1. Nelson JD, Craig JP, Akpek EK, Azar DT, Belmonte C, Bron AJ et al. Tear Film \& Ocular Surface Society (TFOS) Dry Eye Workshop (DEWS) II Introduction. Ocul Surf 2017;15(3):269-275. DOI: 10.1016/j. jtos.2017.05.005. 
2. Stapleton F, Alves M, Bunya VY, Jalbert I, Lekhanont K, Malet F et al. Tear Film \& Ocular Surface Society (TFOS) Dry Eye Workshop (DEWS) II Epidemiology report, Ocul Surf 2017;15(3):334-365. DOI: 10.1016/j. jtos.2017.05.003.

3. Patil SD, Trivedi HR, Parekh NV, Jignesh J. Evaluation of dry eye in computer users. Int I Community Med Public Health 2016;3(12):3403-3407. DOI: 10.18203/23946040.ijcmph20164264.

4. Farrand KF, Fridman M, Stillman IÖ, Schaumberg DA. Prevalence of diagnosed dry eye disease in the United States among adults aged 18 years and older. Am J Ophthalmol 2017;182:90-98. DOI: 10.1016/j. ajo.2017.06.033.

5. Akyol N. Modern life and dry eye. Turkiye Klinikleri J Ophthalmol - Special Topics, 2013;6(3):30-35.

6. Sullivan DA, Rocha EM, Aragona P, Clayton JA, Ding J, Golebiowski B et al. Tear Film \& Ocular Surface Society (TFOS) Dry Eye Workshop (DEWS) II Sex, gender, and hormones report. Ocul Surf 2017;15(3):284333. DOI: $10.1016 / j . j t o s .2017 .04 .001$.

7. Wolkoff P. External eye symptoms in indoor environments. Indoor Air 2017;27(2):246-260. DOI: 10.1111/ina.12322.

8. Salimifard P, Rim D, Gomes C, Kremer P, Freihaut JD. Resuspension of biological particles from indoor surfaces: Effects of humidity and air swirl. Sci Total Environ 2017;583:241-247.

9. Coles-Brennan C, Sulley A, Young G. Management of digital eye strain. Clin Exp Optom, 2019;102(1):18-29. DOI: 10.1111/ CX0.12798

10. Belmonte C, Nichols JJ, Cox SM, Brock JA, Begley CG, Bereiter DA et al. Tear Film \& Ocular Surface Society (TFOS) Dry Eye Workshop (DEWS) II Pain and sensation report. Ocul Surf 2017;15(3):404-437. DOI: 10.1016/j.jtos.2017.05.002.

11. Koh S, Tung $\mathrm{Cl}$, Inoue $\mathrm{Y}$, Jhanji V. Effects of tear film dynamics on quality of vision. $\mathrm{Br}$ J Ophthalmol 2018;102(12):1615-1620. DOI: 10.1136/ bjophthalmol-2018-312333.

12. Azuma K, Ikeda K, Kagi N, Yanagi U, Osawa H. Physicochemical risk factors for buildingrelated symptoms in air-conditioned office buildings: Ambient particles and combined exposure to indoor air pollutants. Sci Total Environ 2018;616:1649-1655.

13. Van Tilborg MM, Murphy PJ, Evans KS. Impact of dry eye symptoms and daily activities in a modern office. Optom Vis Sci 2017;94(6):688693. DOI: $10.1097 /$ OPX.0000000000001086.

14. Wolkoff P. The mystery of dry indoor air - an overview. Environ Int 2018;121(2):1058-1065. DOI: 10.1016/j.envint.2018.10.053
15. Nichols KK, Foulks GN, Bron AJ, Glasgow BJ, Doğru M, Tsubota K et al. The international workshop on meibomian gland dysfunction: Executive summary. Investigative Ophthalmology Vis Sci 2011;52:1922-1929.

16. Tiskaoglu NS, Yazıcı A, Karlıdere T, Sari E, Oguz EY, Musaoglu M, et al. Dry eye disease in patients with newly diagnosed depressive disorder. Curr Eye Res 2017;42(5):672-676. DOI: 10.1080/02713683.2016.1236966

17. Rouen PA, White ML. Dry eye disease: Prevalence, assessment, and management Home Healthc Now 2018;36(2):74-83. DOI: 10.1097/NHH.0000000000000652.

18. Smedbold HT, Ahlen C, Norbäck D, Hilt B. Sign of eye irritation in female hospital workers and the indoor environment. Indoor Air 2001;11(4):223-231.

19. Castellanos-González JA, Torres-Martínez V, Martínez-Ruiz A, Fuentes-Orozco C, RendónFélix, J, Irusteta-Jiménez L et al. Prevalence of dry eye syndrome in residents of surgical specialties. BMC Ophthalmol 2016;16:108. DOI: 10.1186/s12886-016-0292-3.

20. Reyhan AH, Bilgin B. Yoğun bakim hemşirelerinde nöbet sonrasi gözyaşi bulgularinin değerlendirilmesi [Assessment of tear film parameters after working overnight in ıntensive care nurses]. Kırıkkale Üni Tıp Fak Derg [Kırıkkale University Faculty of Medicine Journal], 2018;20(3):280-286.

21. Janki S, Mulder EEAP, Jzermans JNM, Tran TCK. Ergonomics in the operating room. Surg Endosc 2017;31(6):2457-2466.

22. Gutierrez-Diez MC, Benito-Gonzalez MA, Sancibrian R, Gandarillas-Gonzalez MA, Redondo-Figuero C, Manuel-Palazuelos JC. A study of the prevalence of musculoskeletal disorders in surgeons performing minimally invasive surgery. Int J Occup Saf Ergon 2018;24(1):111-117.

23. Anshel JR. Visual ergonomics in the workplace. AAOHN Journal 2007;55:415-420.

24. Bron AJ, De Paiva CS, Chauhan SK, Bonini S, Gabison EE, Jain S et al. Tear Film \& Ocular Surface Society (TFOS) Dry Eye Workshop (DEWS) II Pathophysiology report. Ocul Surf 2017;15(3):438-510.

25. Messmer EM. The pathophysiology, diagnosis and treatment of dry eye disease. Dtsch Arztebl Int 2015;112(5):71-81.

26. Arita R, Fukuoka S, Morishige N. New insights Into the lipid layer of the tear film and meibomian glands. Eye Contact Lens 2017;43(6):335-339.

27. Yeh TN, Graham AD, Lin MC. Relationships among tear film stability, osmolarity and dryness symptoms. Optom Vis Sci 2015;92(9): 264-272. DOI: 10.1097/ OPX.0000000000000649.
28. Willcox MDP, Argüeso P, Georgiev GA, Holopainen JM, Laurie GW, Millar TJ et al. Tear Film \& Ocular Surface Society (TFOS) Dry Eye Workshop (DEWS) II Tear film report. Ocul Surf 2017;15(3):366-403.

29. Gümüş K. The epidemiology and pathophysiology of dry eye disease. MN Oftalmoloji, 2018;25:5-11

30. Wolkoff P, Karcher T, Horst M. Problems of the 'outer eyes' in the office environment - an ergophthalmologic approach. JOEM 2012;54(5):621-631.

31. Wang MT, Tien L, Han A, Lee JM, Kim D, Markoulli $M$ et al. Impact of blinking on ocular surface and tear film parameters. Ocul Surf 2018;16(4):424-429.

32. Portello JK, Rosenfield M, Chu CA. Blink rate, incomplete blinks and computer vision syndrome. Optom Vis Sci 2013;90(5):482-487.

33. Hirota M, Uozato H, Kawamorita T, Shibata Y, Yamamoto S. Effect of incomplete blinking on tear film stability. Optom Vis Sci 2013;90(7):650-657.

34. Eijkemans MJC, Houdenhoven M, Nguyen T, Boersma E, Steyerberg EW, Kazemier $\mathrm{G}$. Predicting the unpredictable: A new prediction model for operating room times using Individual characteristics and the surgeon's estimate. Anesthesiology 2010;112(1):41-49. DOI: $10.1097 /$ ALN.0b013e3181c294c2.

35. Alex A, Edwards A, Hays JD, Kerkstra M, Shih $A$, de Paiva CS et al. Factors predicting the ocular surface response to desiccating environmental stress. Invest Ophthalmol Vis Sci 2013;54(5):3325-32. DOI: 10.1167/iovs.1211322.

36. Noguchi C, Koseki H, Horiuchi H, Yonekura A, Tomita M, Higuchi T et al. Factors contributing to airborne particle dispersal in the operating room. BMC Surg 2017;17(1):78-92.

37. Friedrich L, Boeckelmann I. Hygienische Abnahmeprüfungen raumlufttechnischer Anlagen unter Ruhebedingungen nach DIN 1946-4:1999-03 - eine retrospektive Auswertung [Hygienic inspections of ventilation systems under resting conditions (According to DIN 1946-4:1999-03) - a retrospective assessment]. Zentralbl Chir [Central sheet for Surgery] 2018;143(6):617624. DOI: 10.1055/s-0043-120916.

38. McHugh SM, Hill AD, Humphreys H. Laminar airflow and the prevention of surgical site infection: More harm than good? Surgeon 2015;13(1):52-58. DOI: 10.1016/j. surge.2014.10.003.

39. Pada S, Perl TM. Operating room myths: What is the evidence for common practices. Curr Opin Infect Dis 2015;28(4):369-374. DOI: 10.1097/QCO.0000000000000177. 
40. Bischoff P, Kubilay NZ, Allegranzi B, Egger $M$, Gastmeier P. Effect of laminar airflow ventilation on surgical site infections: A systematic review and meta-analysis. Lancet Infect Dis 2017;17(5):553-561. DOI: 10.1016/ S1473-3099(17)30059-2.

41. American Society of Heating, Refrigerating and Air-Conditioning Engineers (ASHRAE). Interpretation IC 170-2013-1 of ANSI/ ASHRAE/ASHE Standard 170-2013 Ventilation of Health Care Facilities [Internet]. Peachtree Corners, GA: ASHRAE; 2014 [cited 2021 January 02]. Available from: www.ashrae.org/technical-resources/ standards-and-guidelines/standardsinterpretations/interpretations-forstandard-170-2013.

42. International Organization for Standardization (ISO). ISO 14644-1:2015 Cleanrooms and associated controlled environments - Part 1: Classification of air cleanliness by particle concentration [Internet]. Geneva: ISO: 2015 [cited 2021 January 02]. Available from: www.iso.org/ standard/53394.html.

43. Katz JD. Control of the environment in the operating room. Anesth Analg 2017;125(4):1214-1218.

44. Centers for Disease Control and Prevention (CDC). Environmental Infection Control Guidelines: Guidelines for Environmental Infection Control in Health-Care Facilities (2003) [Internet]. Atlanta: CDC; 2003 [cited 2021 January 02]. Available from: www.cdc.gov/infectioncontrol/guidelines/ environmental/index.html.

45. Pasquarella C, Barchitta M, D'Alessandro D, Cristina ML, Mura I, Nobile M et al. Heating, ventilation and air conditioning (HVAC) system, microbial air contamination and surgical site infection in hip and knee arthroplasties: The GISIO-SItI Ischia study. Ann Ig 2018;30(5):22-35.

46. Alsved M, Civilis A, Ekolind P, Tammelin $A$, Andersson AE, Jakobsson J et al. Temperature-controlled airflow ventilation in operating rooms compared with laminar airflow and turbulent mixed airflow. J Hosp Infect, 2018;98(2):181-190.

47. Totaro M, Costa AL, Casini B, Profeti S, Gallo $A$, Frendo $L$ et al. Microbiological air quality in heating, ventilation and air conditioning systems of surgical and intensive care areas: The application of a disinfection procedure for dehumidification devices. Pathogens, 2019;8(1):1-8.

48. Abusharha AA, Pearce El, Fagehi R. Effect of ambient temperature on the human tear film. Eye Contact Lens 2016;42(5):308-312. DOI: $10.1097 /$ ICL.0000000000000210.
49. Alves M, Novaes P, Morraye MA, Reinach PS, Rocha EM. Is dry eye an environmental disease? Arq Bras Oftalmol 2014;77(3):193200.

50. Zhang X, Vimalin MJ, Qu Y, He X, Ou S, Bu J et al. Dry eye management: Targeting the ocular surface microenvironment. Int J Mol Sci 2017;18(7):1398. DOI: 10.3390/ijms18071398.

51. Curlin J, Herman CK. Current State of Surgical Lighting. Surg J (NY) 2020;6(2):87-97.

52. Lim SR, Kang D, Ogunseitan OA, Schoenung JM. Potential environmental impacts from the metals in incandescent, compact fluorescent lamp (CFL), and light-emitting diode (LED) bulbs. Environ Sci Technol 2011;45(1):320-327.

53. Hawesa BK, Brunyé TT, Mahoney CR, Sullivan JM, All CD. Effects of four workplace lighting technologies on perception, cognition and affective state. Int J Ind Ergon 2012;42(1):122128.

54. Pachito DV, Eckeli AL, Desouky AS, Corbett MA, Partonen T, Rajaratnam SM et al. Workplace lighting for improving alertness and mood in daytime workers. Cochrane Database Syst Rev 2018;3, CD012243.

55. Lin KH, Su CC, Chen YY, Chu PC. The effects of lighting problems on eye symptoms among cleanroom microscope workers. Int J Environ Res Public Health 2019;16(1):101. DOI 10.3390/ijerph16010101.

56. Vazquez-Ferreiro P, Carrera Hueso FJ, Alvarez LB, Diaz-Rey M, Martinez-Casal $X$, Ramón Barrios MA. Evaluation of formaldehyde as an ocular irritant: A systematic review and meta-analysis. Cutan Ocul Toxicol 2019;38(2):169-175. DOI: 10.1080/15569527.2018.1561709.

57. Jung SJ, Mehta JS, Tong L. Effects of environment pollution on the ocular surface. Ocul Surf 2018;16(2):198-205.

58. Slaughter RJ, Watts M, Vale JA, Grieve JR, Schep LJ. The clinical toxicology of sodium hypochlorite. Clin Toxicol 2019;57(5):303-311. DOI: $10.1080 / 15563650.2018 .1543889$.

59. Lai LJ, Hsu WH, Wu AM, Wu JH. Ocular injury by transient formaldehyde exposure in a rabbit eye model. PLoS One 2019;8(6):e66649. DOI: 10.1371/journal.pone.0066649.

60. Vitoux MA, Kessal K, Baudouin C, Laprévote O, Parsadaniantz S, Achard S et al. Formaldehyde gas exposure increases inflammation in an in vitro model of dry eye. Toxicol Sci 2018;165(1):108-117.

61. Pacenti M, Dugheri S, Boccalon P, Arcangeli G, Dolara P, Cupelli V. Air monitoring and assessment of occupational exposure to peracetic acid in a hospital environment. Ind Health 2010;48(2):217-221.
62. Pechacek N, Osorio M, Caudill J, Peterson B. Evaluation of the toxicity data for peracetic acid in deriving occupational exposure limits: A minireview. Toxicol Lett 2015;233(1):45-57.

63. Hawley B, Casey M, Virji MA, Cummings KJ, Johnson A, Cox-Ganser J. Respiratory symptoms in hospital cleaning staff exposed to a product containing hydrogen peroxide, peracetic acid and acetic acid. Ann Work Expo Health 2017;62(1):28-40.

64. Pougnet R, Lucas D, Durand-Moreau Q, Dewitte JD, Loddé B. Occupational bronchial disease caused by peracetic acid-hydrogen peroxide mixture: Discussion about reactive airways dysfunction syndrome. Occup Med 2019;69(8):635-636. DOI: 10.1093/occmed/ kqz130.

65. Casey ML, Hawley B, Edwards N, Cox-Ganser $\mathrm{JM}$, Cummings KJ. Occupational health risks associated with the use of germicides in health care. Am J Infect Control 2016;44:8589.

66. Weber DJ, Consoli SA, Rutala WA. Occupational health risks associated with the use of germicides in health care. Am J Infect Control 2016;44:85-89.

67. Walters GI, Burge PS, Moore VC, Thomas MO, Robertson AS. Occupational asthma caused by peracetic acid-hydrogen peroxide mixture. Occup Med 2019;69(4):294-297.

68. Fencl JL. Guideline implementation: Surgical smoke safety. AORN J 2017;105(5):488-497.

69. Okoshi K, Kobayashi K, Kinoshita K, Tomizawa Y, Hasegawa S, Sakai Y. Health risks associated with exposure to surgical smoke for surgeons and operation room personnel. Surg Today 2015;45(8):957-65.

70. Sisler J, Shaffer J, Soo J, LeBouf R, Harper M, Qian Y. In vitro toxicological evaluation of surgical smoke from human tissue. J Occup Med Toxicol 2018;13:1-12.

71. York Y, Autry M. Surgical smoke: Putting the pieces together to become smoke-free. AORN J 2018;107(6):692-703. DOI: 10.1002/ aorn.12149.

72. Ilce A, Yuzden GE, Yavuz van Giersbergen M. The examination of problems experienced by nurses and doctors associated with exposure to surgical smoke and the necessary precautions. I Clin Nurs 2017;26(11-12):1555-1561.

73. Choi SH, Kwon TG, Chung SK, Kim TH. Surgical smoke may be a biohazard to surgeons performing laparoscopic surgery. Surg Endosc 2014;28(8):2374-2380.

74. Bree K, Barnhill S, Rundell W. The dangers of electrosurgical smoke to operating room personnel: A review. Workplace Health Saf 2017:65(11):517-526. 
75. Tseng HS, Liu SP, Uang SN, Yang LR, Lee SC, Liu YJ et al. Cancer risk of incremental exposure to polycyclic aromatic

hydrocarbons in electrocautery smoke for mastectomy personnel. World J Surg Oncol 2014;12:11-31.

76. Azadgoli B, Baker RY. Laser applications in surgery. Ann Transl Med 2016;4(23):452.

77. Eder SP. Guideline implementation: Energygenerating devices, part 1 - electrosurgery. AORN J 2017;105(3):300-310.

78. Burlingame BL. Guideline implementation: Energy-generating devices, part 2 - lasers. AORN J 2017;105(4). 392-401.

79. Castelluccio D. Implementing AORN recommended practices for laser safety. AORN J 2012;95(5):612-624. 